\title{
Goat lung surfactant for treatment of respiratory distress syndrome among preterm neonates: a multi-site randomized non-inferiority trial
}

\author{
Kajal Jain ${ }^{1}$ - Sushma Nangia ${ }^{2}$ - Vishnu Bhat Ballambattu ${ }^{3} \cdot$ Venkataseshan Sundaram $^{4} \cdot$ M. Jeeva Sankar ${ }^{1}$. \\ Siddharth Ramji ${ }^{5}$ - Sreenivas Vishnubhatla ${ }^{1}$. Anu Thukral ${ }^{1}$ - Yogendra Kumar Gupta ${ }^{1,6}$ • Nishad Plakkal ${ }^{3}$. \\ Mangalabharathi Sundaram ${ }^{7} \cdot$ Mamta Jajoo $^{8} \cdot$ Praveen Kumar $^{4} \cdot$ Kumutha Jayaraman $^{7} \cdot$ Ashish Jain $^{5} \cdot$ Arvind Saili $^{2}$. \\ Anitha Murugesan ${ }^{7}$. Deepak Chawla ${ }^{9}$ Srinivas Murki ${ }^{10} \cdot$ Ruchi Nanavati $^{11}$ - Suman Rao ${ }^{12}$. Umesh Vaidya ${ }^{13}$. \\ Ashish Mehta ${ }^{14} \cdot$ Kamal Arora $^{15}$. Jayashree Mondkar ${ }^{16} \cdot$ Sugandha Arya $^{17} \cdot$ Monika Bahl $^{18} \cdot$ Alpana Utture $^{11}$. \\ Swati Manerkar ${ }^{16} \cdot$ Swarna Rekha Bhat ${ }^{12} \cdot$ Tushar Parikh $^{13} \cdot$ Manish Kumar $^{14} \cdot$ Anurag Bajpai $^{1} \cdot$ Sindhu Sivanandan ${ }^{3}$. \\ Pawandeep Kaur Dhawan ${ }^{18}$. Gayatri Vishwakarma ${ }^{18}$. Sudhakar Bangera ${ }^{18}$. Sumit Kumar ${ }^{18}$. \\ Shridhar Gopalakrishnan ${ }^{19}$ - Atul Jindal ${ }^{20}$. Chandra Kumar Natarajan ${ }^{21}$ - Anumeet Saini ${ }^{2} \cdot$ Sukanya Karunanidhi $^{3}$. \\ Meenakshi Malik ${ }^{4}$ Parul Narang ${ }^{1} \cdot$ Gurkirat Kaur $^{5}$. Chander Prakash Yadav ${ }^{22}$ - Ashok Deorari ${ }^{1}$ - Vinod K. Paul ${ }^{1,23}$. \\ Ramesh Agarwal ${ }^{1}$
}

(c) The Author(s) 2019. This article is published with open access

\begin{abstract}
Objective To investigate the safety and efficacy of goat lung surfactant extract (GLSE) compared with bovine surfactant extract (beractant; Survanta ${ }^{\circledR}$, AbbVie, USA) for the treatment of neonatal respiratory distress syndrome (RDS).

Study design We conducted a double-blind, non-inferiority, randomized trial in seven Indian centers between June 22, 2016 and January 11, 2018. Preterm neonates of 26 to 32 weeks gestation with clinical diagnosis of RDS were randomized to receive either GLSE or beractant. Repeat dose, if required, was open-label beractant in both the groups. The primary outcome was a composite of death or bronchopulmonary dysplasia (BPD) at 36 weeks postmenstrual age (PMA). Interim analyses were done by an independent data and safety monitoring board (DSMB).

Result After the first interim analyses on 5\% enrolment, the "need for repeat dose(s) of surfactant" was added as an additional primary outcome and enrolment restricted to intramural births at five of the seven participating centers. Following second interim analysis after 98 (10\% of 900 planned) neonates were enroled, DSMB recommended closure of study in view of inferior efficacy of GLSE in comparison to beractant. There was no significant difference in the primary outcome of death or BPD between GLSE group $(n=52)$ and beractant group $(n=46)(50.0$ vs. $39.1 \%$; OR 1.5 ; $95 \%$ CI $0.7-3.5 ; p=0.28)$. The need for repeat dose of surfactant was significantly higher in GLSE group (65.4 vs. 17.4\%; OR 9.0; 95\% CI 3.5-23.3; $p<0.001$ ).

Conclusions Goat lung surfactant was less efficacious than beractant (Survanta ${ }^{\circledR}$ ) for treatment of RDS in preterm infants. Reasons to ascertain inferior efficacy of goat lung surfactant requires investigation and possible mitigating strategies in order to develop a low-cost and effective surfactant.
\end{abstract}

Supplementary information The online version of this article (https://doi.org/10.1038/s41372-019-0472-0) contains supplementary material.

Ramesh Agarwal

ra.aiims@gmail.com

Extended author information available on the last page of the article

\section{Introduction}

Surfactant replacement therapy (SRT) forms the cornerstone of management of moderate to severe respiratory distress syndrome (RDS) among preterm neonates and it is associated with reduced mortality and pulmonary air leak $[1,2]$. These benefits have been confirmed through a meta-analysis conducted to study the efficacy and safety of SRT for preterm neonates in low- and middle-income countries 
(LMICs) [3]. Surfactant therapy is cost effective [4] and is included in the World Health Organization's Essential drug list [5]. However the high cost of surfactant has precluded its optimum access in LMICs where $90 \%$ of global burden of neonatal deaths occur due to complications of prematurity. Given India's proven track record of producing high-quality drugs at low cost, development of indigenous surfactant has been listed as an important priority by the Government of India [6].

Natural surfactants used today are sourced from bovine or porcine origin and extracted from minced lung tissue or by lung lavage. Researchers at All India Institute of Medical Sciences (AIIMS), New Delhi, prepared surfactant from slaughtered goat lungs in 1998 by chloroform-methanol extraction method [7]. Subsequently, an Indian pharmaceutical company (Cadisurf $^{\circledR}$; Cadila Pharmaceuticals, Ahmedabad, India) carried out product development further. The goat lung surfactant extract (GLSE) contains phospholipids ( $25 \mathrm{mg} / \mathrm{mL}$ phospholipids) and surfactantassociated proteins $(<1 \%)$. The product underwent independent biochemical standardization by the manufacturer and was found to be identical in composition to beractant (Survanta; AbbVie, USA) with regard to its phospholipid and peptide content. Its biological activity as a surfaceactive agent was documented in in-vitro studies and in a rat lung model of RDS. The product was shown to be microbiologically sterile and no adverse events were documented in animal toxicity studies performed in compliance with Indian regulatory guidelines. The cost of SRT using GLSE was estimated to be less than a tenth of imported surfactants. The product, however, awaited clinical validation. The objective of this study was to compare the safety and efficacy of GLSE with that of the standard bovine lung surfactant (beractant; Survanta ${ }^{\circledR}$ ) in the treatment of RDS.

\section{Methodology}

\section{Study design}

In this multicenter, randomized, double-blind, parallel group, non-inferiority trial, we compared the safety and efficacy of GLSE (Cadisurf ${ }^{\circledR}$, Cadila Pharmaceuticals, Ahmedabad, India) with beractant (Survanta $^{\circledR}$, AbbVie, USA) for the treatment of RDS in preterm neonates. The trial was undertaken at seven tertiary care academic centers in India from June 22, 2016 to January 11, 2018. Five of the participating NICUs were intramural (inborn) units, while the other two exclusively cared for extramural (outborn) neonates. The study protocol was approved by the institutional ethics committee (IEC) of each participating center. The trial was registered with the Clinical Trials
Registry - India (CTRI/2015/07/005968) and ClinicalTrials. gov (NCT02774044).

\section{Participants}

Preterm neonates born at 26-32 weeks' gestation and admitted to any of the participating NICUs were eligible for enrolment if they developed clinical features of RDS (fast breathing or chest retractions) within $6 \mathrm{~h}$ of birth and fulfilled criteria to receive surfactant therapy within $24 \mathrm{~h}$ of birth. The criteria for SRT were any one of the two: (i) $\mathrm{FiO}_{2}$ requirement $40 \%$ or higher while on continuous positive airway pressure (CPAP) to maintain oxygen saturation between 90 and 95\%, (ii) need for intubation and mechanical ventilation because of CPAP failure or severe respiratory distress. Chest X-ray was not mandated prior to SRT. Exclusion criteria were (i) significant perinatal asphyxia, defined as need for chest compressions during resuscitation or metabolic acidosis $(\mathrm{pH}<7.0)$ in umbilical arterial blood gas or arterial blood gas obtained within $1 \mathrm{~h}$ of life, (ii) major congenital anomalies or known chromosomal aberrations, (iii) receipt of prophylactic surfactant, (iv) clinical evidence of pulmonary air leak or pulmonary hemorrhage prior to enrolment, and (v) shock requiring vasopressor support prior to enrolment. Parents of potentially eligible neonates were approached both before and after birth, and written informed consent was obtained from parents or legally acceptable representative prior to enrolment.

\section{Randomization}

Neonates were randomly assigned to receive GLSE or beractant. Randomization lists were prepared by an independent statistician using SAS 9.4 software (SAS Institute Inc., USA). Assignments were stratified according to center and gestational age (26-27 weeks and 28-32 weeks). Within each stratum, a 1:1 allocation ratio and block randomization with variable block sizes (4 to 10) were used. Neonates of multiple births with more than one eligible participant were randomized individually.

\section{Intervention and blinding}

GLSE was supplied in single-use glass vials containing 8 $\mathrm{mL}$ (200 mg phospholipids; $25 \mathrm{mg} / \mathrm{mL}$ ) of the product suspended in preservative-free $0.9 \%$ sodium chloride solution. Beractant (Survanta, AbbVie, USA) was commercially procured. Since the two surfactant products differed in color, consistency, and packaging, an independent team at a central location repacked the vials in identical sealed cardboard boxes and serially labeled them based on the allocation sequence for two gestation strata. They were then 
transported to study centers while maintaining the cold chain.

The research team, parents, data analysis team, monitoring team, and data and safety monitoring board (DSMB) were blinded to the intervention. To ensure blinding of physicians and nurses who administered the surfactant, we employed an innovative method (SOP for blinding provided in Supplementary information). A team of nurses (IP nurses) from the ward adjoining NICU were trained to load surfactant as per the study blinding protocol. On enrolment, the research team summoned an IP nurse who opened the sealed box as per the serial number, drew up the specified amount of surfactant in a specially manufactured opaque syringe, connected an opaque catheter to its nozzle and handed it over to the clinical team at bedside ready for administration. The surfactant loading was performed in a cordoned area of the NICU. After surfactant administration, the IP nurse collected the empty syringe and catheter from the clinicians and sealed all the used material and vial in a bag to be retrieved by the nodal team later.

\section{Procedures}

Surfactant was administered via an opaque catheter passed through the endotracheal tube in four equal aliquots. Post surfactant, neonates were extubated to CPAP (intubation, surfactant administration, and extubation; InSurE) if they had adequate spontaneous respiratory efforts and were hemodynamically stable; else, they were continued on mechanical ventilation and weaned appropriately. Neonates were eligible for repeat dose(s) of surfactant (maximum of three additional doses) at an interval of 4-6 h if they were still intubated, or if oxygen requirement was $40 \%$ or more on nasal CPAP, or at the discretion of the treating physician. For repeat doses in both the groups, open-label beractant (Survanta) was used. Participating NICUs were provided with standard operating procedures (SOP) for the management of neonatal morbidities; however, they were permitted to follow unit protocol, whenever appropriate. Participants were followed up until 36 weeks of postmenstrual age (PMA) or death.

\section{Study outcomes}

The primary outcome of the study was a composite of death or bronchopulmonary dysplasia (BPD) defined physiologically at 36 weeks PMA as requirement of supplemental oxygen of $30 \%$ or more or the need for positive-pressure support to achieve oxygen saturation greater than 90\% [8]. Infants requiring less than $30 \%$ oxygen were labeled to have BPD if they failed an oxygen challenge test [9] done by study personnel masked to treatment assignments. After the first interim analysis, DSMB added need for repeat dose of surfactant as an additional primary outcome. Secondary outcome measures included area under the curve (AUC) for fractional inspired oxygen $\left(\mathrm{FiO}_{2}\right)$ in the first $48 \mathrm{~h}$ post-surfactant, type of respiratory support needed at $72 \mathrm{~h}$ and 7 days of age, occurrence of pulmonary hemorrhage within $48 \mathrm{~h}$ of SRT, clinically important air leak within $72 \mathrm{~h}$ of SRT, grade 3 or 4 intraventricular hemorrhage (IVH), periventricular leukomalacia (PVL) - cystic and noncystic, sepsis in the first week of life, retinopathy of prematurity (ROP) requiring treatment, mortality within 28 days of life, days on respiratory support (mechanical ventilation and CPAP), and duration of hospital stay. The various study outcomes and their definitions are provided in Supplementary information. Area under curve of $\mathrm{FiO}_{2}$ provided a comprehensive summary of the hourly oxygen requirements in the first $48 \mathrm{~h}$ after administration of surfactant. The curve was plotted for each neonate and the mean for all neonates was calculated for single summary index.

\section{Monitoring of study}

Quality assurance and quality control systems were established to ensure that trial conduct, data generation, data recording, and reporting were done in compliance with the protocol, good clinical practice standards and applicable regulatory requirements. All investigators and site teams were trained on the study protocol, trial related procedures, information pertaining to investigational products, procedure for reporting serious adverse events (SAEs), and SOPs for completing case record forms (CRF). The study team maintained adequate and accurate records using site file, source documents and logs designed to capture clinical data. All study data were first captured manually in CRF and then transcribed onto the electronic CRF at sites. (Datasets are available upon request from the corresponding author.) Site users were trained on Accelient study database (Trianz, Acceliant eClinical Suite, Bengaluru). Site monitoring visits were undertaken on regular basis and information recorded in the CRF was verified against source documents. Discrepancies observed during quality checks were flagged for the site investigators to verify and reconcile. Death and other SAEs were reported to the regulatory authorities and causality assessment was carried out. The DSMB monitored the progress of study and safety data for prespecified outcomes including death and other SAEs. The study had prespecified safety stopping bounds and interim analyses were planned after 5, 33, and 66\% enrolment of subjects.

\section{Sample size}

Based on the retrospective data for 1 year provided by the participating centers, the risk of death or BPD among inborn preterm neonates $\leq 32$ weeks gestation was 
estimated to be $40 \%$. The sample size was computed considering a non-inferiority margin for GLSE of $10 \%$ higher than this baseline rate. For an alpha error of 5\% and power of $90 \%$, the sample size required was 412 infants per group and we increased the sample size to 450 per group (total sample of 900) to account for a $10 \%$ drop out rate after enrolment.

\section{Statistical analysis}

All data were analyzed according to intention-to-treat principle using Stata software (version 14.2). Continuous data were summarized using mean and standard deviation or median and interquartile range, as appropriate. Categorical data were summarized using frequency and percentage. Student's unpaired $t$ test or Wilcoxon Rank Sum test was used for comparison of continuous data and Chisquare or Fisher's exact test was applied for comparison of categorical data. Multivariable logistic regression analysis was carried out for the outcome variables after adjustment for study center and baseline characteristics that were substantially different between the two groups ( $>10 \%$ difference) on univariate analysis. Risk difference along with $95 \% \mathrm{CI}$ was calculated to assess the noninferiority.

\section{Results}

The first interim safety analysis was conducted after the enrolment of initial $5 \%$ of neonates (45 neonates with 42 enroled at five inborn centers). The DSMB analyzed the data by groups $\mathrm{A}$ and $\mathrm{B}$ while still being blinded to the nature of intervention. There was no difference in death or BPD but the need for repeat dose of surfactant was different between the two groups. Because the two groups differed in baseline characteristics, no definite conclusions could be made. The DSMB recommended to restrict enrolment to inborn neonates, to add 'need for repeat dose of surfactant' as an additional primary outcome, and to conduct an additional interim analysis after completing $10 \%$ enrolment. In the second interim analysis after 98 inborn neonates completed follow up, the DSMB recommended that the study be closed to further enrolment in view of poor efficacy of GLSE in comparison with beractant. The recruitment status at different sites at the time of study closure is provided in Supplementary information.

At the time of study closure, 285 preterm neonates $\leq 32$ weeks gestation had been assessed for eligibility, and 101 from seven (five inborn and two outborn) centers were randomized to either of the groups. As directed by DSMB, outborn neonates $(n=3)$ were not included in the final analysis. Thus 98 inborn neonates randomized to the GLSE group ( $n=52)$ or the beractant group $(n=46)$ were analyzed (Fig. 1). The baseline characteristics were comparable between the two groups except a higher percentage of male neonates enroled in the GLSE group (78.3 vs. $48.1 \%$; $p=0.002$ ) (Table 1). The median age at eligibility and receipt of surfactant were similar, with most neonates receiving surfactant within $2 \mathrm{~h}$ of being eligible in both the groups.

There was no significant difference in the primary outcome of death or BPD between the GLSE and beractant groups (50.0 vs. $39.1 \%$; OR $1.5 ; 95 \%$ CI $0.7-3.5 ; p=0.28$ ). The need for repeat dose of surfactant was higher in the GLSE group (65.4 vs. 17.4\%; OR 9.0; 95\% CI 3.5-23.3; $p<0.001$ ) (Table 2).The mean number of surfactant doses in the GLSE group was $1.9 \pm 0.8$ compared with $1.2 \pm 0.6$ in the beractant group ( $p=0.001)$ (Table 3).

Among secondary outcomes, average $\mathrm{FiO}_{2}$ required during first $48 \mathrm{~h}$ post-surfactant administration or until death (if died within $48 \mathrm{~h}$ ) was higher in GLSE group $(50.5 \pm 21.2$ vs. $33.3 \% \pm 14.5 ; 17.2 \%, 95 \%$ CI $9.8-24.6, p<0.001)$. The duration of mechanical ventilation in first $48 \mathrm{~h}$ postsurfactant administration was also higher in GLSE group (28.5 vs. $16.0 \mathrm{~h}$; mean difference 12.5 ; $95 \%$ CI $4.8-20.1$, $p=0.001$ ) (Table 4). Other secondary outcomes and SAEs including pulmonary hemorrhage within $48 \mathrm{~h}$ of surfactant administration, air leak within $72 \mathrm{~h}$ of surfactant administration, sepsis in first 7 days after birth, PIVH, necrotizing enterocolitis, hemodynamically significant patent ductus arteriosus (PDA), BPD, ROP requiring treatment, duration of NICU stay and hospital stay were comparable between the groups (Table 4). No case of PVL was noted in either group.

A multivariable analysis of outcomes was performed adjusting for study center and baseline characteristics that were substantially different ( $>10 \%$; even if statistically not significant) between two groups namely, gender, rupture of membranes for more than $18 \mathrm{~h}$, antepartum hemorrhage, need for positive pressure ventilation after birth, use of delivery room CPAP and InSurE. There was no difference in mortality between the groups $(p=0.82)$ but need for the repeat dose of surfactant (Table 4), need for mechanical ventilation within $24 \mathrm{~h}$ and average $\mathrm{FiO}_{2}$ required in first $48 \mathrm{~h}$ after surfactant administration (Fig. 2) was significantly higher in the GLSE group compared with beractant group (Table 5).

\section{Discussion}

The GLSE trial is the first to evaluate an indigenous lowcost surfactant extracted from goat lungs for neonatal RDS. The study was prematurely terminated after enrolment of $10 \%$ of planned sample size in view of poor efficacy of 


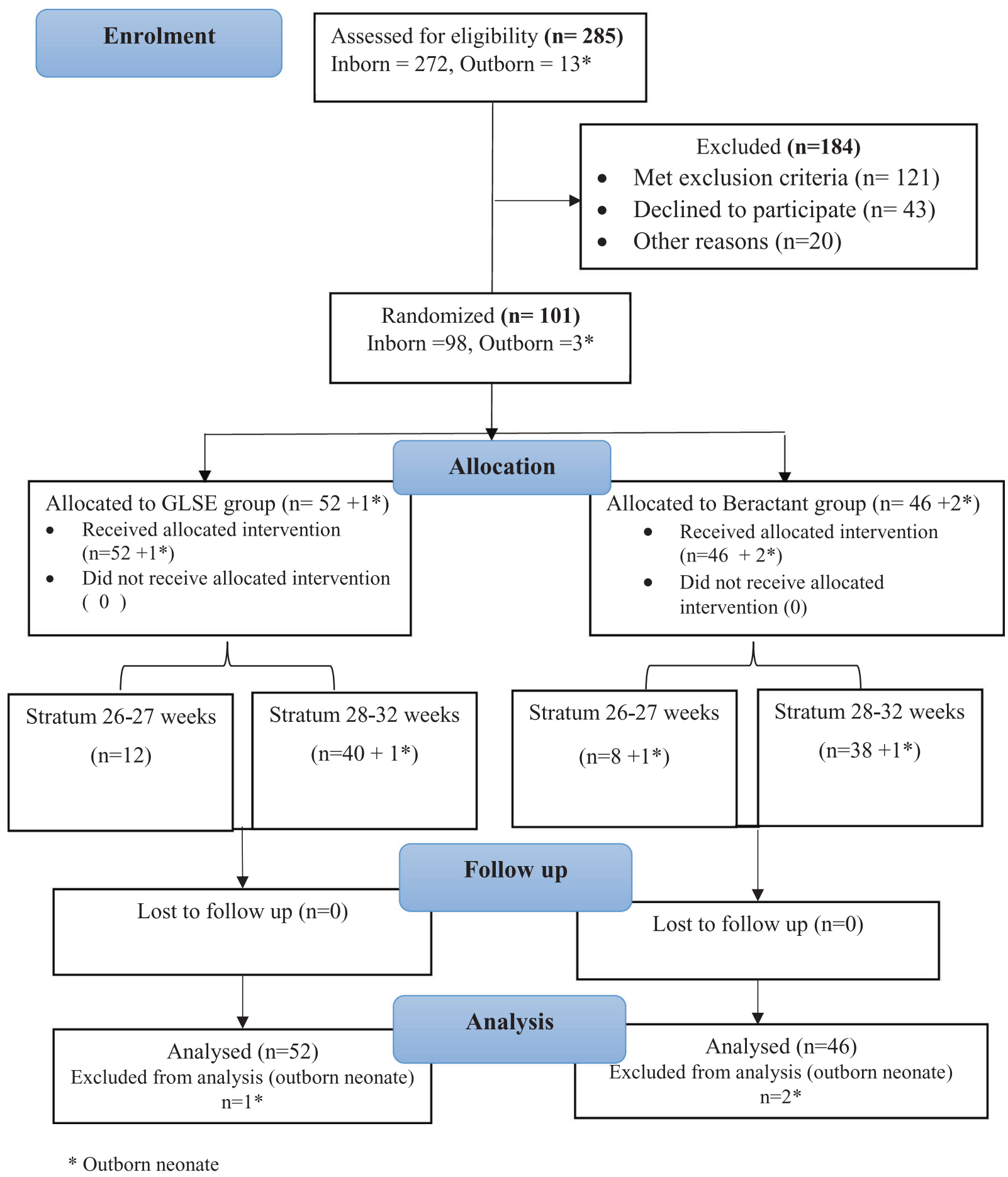

Fig. 1 Participant flow

GLSE when compared with beractant. While the composite primary outcome of death or BPD was not different between the two groups, the need for repeat doses of openlabel surfactant was higher in the GLSE group. Other objective pointers of poor efficacy included the higher need for mechanical ventilation within $24 \mathrm{~h}$ and higher average $\mathrm{FiO}_{2}$ required in first $48 \mathrm{~h}$ post-surfactant administration in the GLSE group.
The high cost of surfactant therapy continues to be a major barrier in LMIC countries. The demand for an indigenous surfactant that is efficacious and safe yet cheap remains a top research priority in these countries [6]. The Instituto Butantan in Brazil developed a low-cost porcine surfactant using a new technology that involved macerating swine lung followed by organic extraction and cellulose adsorption [10]. A multicenter RCT in Brazil randomized 
Table 1 Baseline characteristics of the enroled infants

\begin{tabular}{|c|c|c|c|}
\hline Characteristic & $\operatorname{GLSE}(n=52)$ & Beractant $(n=46)$ & $p$-value \\
\hline \multicolumn{4}{|l|}{ Maternal } \\
\hline Antibiotics in 7 days before delivery & $18(34.6)$ & $18(39.1)$ & 0.64 \\
\hline Gestational diabetes & $6(11.5)$ & $3(6.5)$ & 0.39 \\
\hline \multicolumn{4}{|l|}{ Antenatal steroids } \\
\hline None/unknown & $8(15.4)$ & $8(17.4)$ & \\
\hline Incomplete & $17(32.7)$ & $18(39.1)$ & 0.70 \\
\hline Complete & $27(51.9)$ & $20(43.5)$ & \\
\hline \multirow[t]{2}{*}{ Clinical chorioamnionitis } & $(n=47)$ & $(n=43)$ & 0.35 \\
\hline & $3(6.4)$ & $1(2.3)$ & \\
\hline Rupture of membranes for $\geq 18 \mathrm{~h}$ & $16(30.8)$ & $8(17.4)$ & 0.12 \\
\hline Cesarean delivery & $23(44.2)$ & $18(39.1)$ & 0.61 \\
\hline Antepartum hemorrhage & $14(26.9)$ & $7(15.2)$ & 0.16 \\
\hline \multicolumn{4}{|l|}{ Neonatal } \\
\hline Gestation in weeks & $29.2 \pm 1.9$ & $29.2 \pm 1.8$ & 0.84 \\
\hline Birth weight, $g$ & $1192 \pm 312$ & $1156 \pm 298$ & 0.56 \\
\hline Small for gestational age & $6(11.5)$ & $5(10.9)$ & 0.63 \\
\hline Male gender & $25(48.1)$ & $36(78.3)$ & 0.002 \\
\hline Multiple births & $13(25.0)$ & $12(26.1)$ & 0.90 \\
\hline Positive pressure ventilation (PPV) at birth & $32(61.5)$ & $22(47.8)$ & 0.17 \\
\hline Delayed cord clamping & $6(11.5)$ & $6(13.1)$ & 0.82 \\
\hline Delivery room CPAP & $22(42.3)$ & $24(52.2)$ & 0.33 \\
\hline Median age at eligibility, $\mathrm{h}$ & $1.0(0.2,2)$ & $1.5(1,3.8)$ & 0.82 \\
\hline Median age at surfactant administration, $\mathrm{h}$ & $2.4(1.7,4.5)$ & $2.4(1.8,4.7)$ & 0.61 \\
\hline InSurE ${ }^{a}$ & $29(55.8)$ & $32(69.6)$ & 0.16 \\
\hline
\end{tabular}

Data expressed in $n(\%)$, mean $\pm \mathrm{SD}$, or median (IQR)

${ }^{\mathrm{a}}$ Intubation-surfactant-extubation within $30 \mathrm{~min}$ of completion of surfactant administration

Table 2 Primary outcomes and the components of the composite primary outcome

\begin{tabular}{lcccc}
\hline Outcome & GLSE group $(n=52)$ & Beractant $(n=46)$ & OR (95\% CI) & $\begin{array}{l}\text { Risk difference Beractant } \\
- \text { GLSE (95\% CI) }\end{array}$ \\
\hline Death or BPD at 36 weeks PMA & $26(50.0)$ & $18(39.1)$ & $1.5(0.7-3.5)$ & $-10.8(-30.5,8.7)$ \\
Repeat dose of surfactant & $34(65.4)$ & $8(17.4)$ & $9.0(3.5-23.3)$ & $-48.0(-64.9,-31.0)$ \\
Death & $21(40.4)$ & $14(30.4)$ & $1.5(0.7-3.6)$ & $-9.94(-28.7,8.9)$ \\
BPD & $5 / 31(16.1)$ & $4 / 32(12.5)$ & $1.6(0.6-4.9)$ & $-3.6(-20.9,13.7)$ \\
\hline
\end{tabular}

$B P D$ bronchopulmonary dysplasia, $P M A$ postmenstrual age, $O R$ odds ratio

327 infants to receive Butantan or standard surfactants (Survanta or Curosurf). There was no difference in the primary outcome of mortality at $72 \mathrm{~h}$ of life (14.1 vs. $14.1 \% ; p=0.98$ ) or on day 28 of life (39.8 vs. $33.3 \% ; p=$ 0.24 ) between Butantan and control groups. More neonates in the Butantan group required supplemental oxygen on day 28 of life ( 57 vs. $45 \%, p=0.05$ ). Neonates in the Butantan group also required more doses of surfactant $(2.0 \pm 0.8$ vs. $1.5 \pm 0.7 ; p<0.001)$ and had a significantly higher incidence of pulmonary interstitial emphysema and PDA compared with controls.
In our study, a significantly higher number of GLSE infants $(65 \%)$ required repeat doses of surfactant compared with $17 \%$ in the beractant group. In general, about a third of infants with RDS may require additional surfactant doses due to sub-optimal response to first dose [11, 12]. However, this number can increase to $50 \%$ if RDS is severe or additional complicating factors like pulmonary air leak, asphyxia, sepsis, or PDA are noted [13]. In preterm neonates with clinical presentation of respiratory distress, differentiating RDS (due to surfactant deficiency) from earlyonset sepsis within a limited time frame is always a 
challenge. Since the incidence of sepsis and other complicating factors were comparable in the two groups, the poor efficacy of GLSE could be attributed to the product itself rather than due to host factors.

Table 3 Surfactant doses received in GLSE and Beractant groups

\begin{tabular}{llll}
\hline Characteristic & $\begin{array}{l}\text { GLSE } \\
(n=52)\end{array}$ & $\begin{array}{l}\text { Beractant } \\
(n=46)\end{array}$ & $p$-value \\
\hline $\begin{array}{l}\text { No. of surfactant doses received } \\
\text { (including the first IP dose) }\end{array}$ & $18(34.6)$ & $38(82.6)$ & \\
1 & $19(36.5)$ & $7(15.2)$ & $<0.001$ \\
2 & $15(28.8)$ & $1(2.2)$ & \\
$\geq 3$ & $1.94 \pm 0.8$ & $1.22 \pm 0.6$ & $<0.001$ \\
Mean number of surfactant doses \\
received & $(n=34)$ & $(n=8)$ & \\
Age at second dose (h) & $11.5 \pm 5.8$ & $13.6 \pm 5.4$ & 0.36 \\
$\quad$ Mean \pm SD & $9.8(7.8,13.4)$ & $12.2(710,16.6)$ & \\
Median (IQR) & $(n=15)$ & $(n=1)$ & - \\
Age at third dose (h) & $29.0 \pm 19.7$ & 19.6 & \\
$\quad$ Mean \pm SD & $17.6(13,47.2)$ & 19.6 & - \\
Median (IQR) & 0 & $(n=1)$ & \\
Mean age at fourth dose (h) & & 28.2 & \\
& & & \\
\hline
\end{tabular}

IP Investigational product
Despite being safe and efficacious in animal studies, efficacy of goat lung surfactant was poor when studied in human subjects in our trial. Potential reasons include differences in preparation, processing, or purification techniques, altered biophysical effects in human subjects, inadequate dosage, or increased susceptibility to inactivation by various bio-molecules in the host. Differences in surfactant composition may explain to a certain extent the variations in physio-structural and physiological properties noted in vivo at the alveolar air-liquid interface [14]. Poractant alfa, a minced porcine lung extract has a higher phospholipid content $(76 \mathrm{mg} / \mathrm{mL})$ compared with bovine lung preparations $(25 \mathrm{mg} / \mathrm{mL})$ [15]. It also has a higher content of plasmalogens, a component that improves the surface properties of phospholipid and surfactant protein $B$ (SP-B). Recent work has shown that surfactants with low surface viscosity have better function as it allows a more homogeneous distribution of densely packed lipids during expiration [11]. Minor surfactant components like plasmalogens and polyunsaturated fatty acid containing phospholipids play a crucial role in minimizing surface viscosity. Although it is unclear if these physico-chemical variations in surfactant translate into clinically relevant outcomes in

Table 4 Secondary outcomes

\begin{tabular}{|c|c|c|c|c|}
\hline Secondary outcome & GLSE $(n=52)$ & Beractant $(n=46)$ & $\mathrm{OR} /$ mean difference $(95 \% \mathrm{CI})$ & $p$-value \\
\hline $\begin{array}{l}\text { Area under curve (AUC) for } \mathrm{FiO}_{2} 0-48 \mathrm{~h} \text { of surfactant } \\
\text { administration }\end{array}$ & $2055 \pm 793$ & $1511 \pm 697$ & 543 (242 to 845$)$ & 0.005 \\
\hline $\begin{array}{l}\text { Average } \mathrm{FiO}_{2}(\%) \text { required during first } 48 \mathrm{~h} \text { or until death after } \\
\text { surfactant administration }^{\mathrm{a}}\end{array}$ & $50.5 \pm 21.2$ & $33.3 \pm 14.5$ & $17.2(9.8$ to 24.6$)$ & $<0.001$ \\
\hline $\begin{array}{l}\text { Cumulative duration of mechanical ventilation in first } 48 \mathrm{~h} \text { after } \\
\text { surfactant administration }\end{array}$ & $28.5 \pm 19.1$ & $16 \pm 19$ & $12.5(4.8$ to 20.1$)$ & 0.002 \\
\hline Pulmonary hemorrhage within $48 \mathrm{~h}$ of surfactant administration & $5(9.6)$ & $3(6.5)$ & $1.5(0.3-6.7)$ & 0.58 \\
\hline Air leak within $72 \mathrm{~h}$ of surfactant administration & $3(5.8)$ & 0 & - & - \\
\hline \multicolumn{5}{|l|}{ Sepsis in 7 days } \\
\hline Culture positive & $6(11.5)$ & $2(4.4)$ & $1.7(0.9-2.5)$ & \\
\hline Culture negative & $8(15.4)$ & $5(10.9)$ & $2.3(1.4-3.2)$ & 0.18 \\
\hline No sepsis & $38(73.1)$ & $39(84.8)$ & & \\
\hline Intraventricular hemorrhage (IVH) & $9(17.3)$ & $3(6.5)$ & $3(0.8-11.8)$ & 0.12 \\
\hline Necrotizing enterocolitis stage $\geq 2$ & $1(1.9)$ & $1(2.2)$ & $0.9(0.1-14.5)$ & 0.93 \\
\hline Hemodynamically significant PDA & $10(19.2)$ & $10(21.7)$ & $0.8(0.3-2.3)$ & 0.76 \\
\hline Cystic periventricular leukomalacia (PVL) & 0 & 0 & - & - \\
\hline ROP requiring laser/surgery/VEGF inhibitor & $3(5.8)$ & $1(2.2)$ & $2.8(0.3-27.4)$ & 0.39 \\
\hline BPD & $n=31$ & $n=32$ & & \\
\hline Moderate & $3(9.7)$ & $2(6.2)$ & & \\
\hline Severe & $2(6.4)$ & $2(6.2)$ & $1.6(0.6-4.9)$ & 0.81 \\
\hline NICU stay (days) & $27.7 \pm 29.2$ & $28.6 \pm 22.5$ & $0.9(-9.6$ to 11.5$)$ & 0.86 \\
\hline Hospital stay (days) & $31.6 \pm 32.0$ & $31.7 \pm 21.9$ & $0.1(-11.0$ to 11.3$)$ & 0.98 \\
\hline \multicolumn{5}{|l|}{ No of participants with } \\
\hline No SAE & $11(21.2)$ & $18(39.1)$ & 1.0 & \\
\hline At least $1 \mathrm{SAE}$ other than death & $20(38.5)$ & $14(30.4)$ & $2.33(0.76-7.3)$ & 0.09 \\
\hline$>1$ SAE including death & $29(55.7)$ & $21(45.7)$ & $2.25(0.8-6.4)$ & 0.08 \\
\hline
\end{tabular}

Data expressed in $n / N(\%)$ or mean \pm SD or median (IQR)

$S A E$ serious adverse event, $V E G F$ vascular endothelial growth factor

${ }^{\text {a}}$ Recorded on hourly basis 
neonates, the understanding calls for a more in-depth analysis of the physio-structural properties of GLSE and whether addition of minor lipid components can enhance its surface-active properties [16].

A meta-analysis of randomized controlled trials comparing various animal-derived surfactants showed reduced risk of mortality, need for repeat doses of surfactant, PDA requiring treatment, and the composite outcome of death or BPD with poractant, compared with bovine surfactants [17]. These benefits were noted when a higher initial dose (200 $\mathrm{mg} / \mathrm{kg}$ ) of poractant was used than $100 \mathrm{mg} / \mathrm{kg}$ of either poractant or bovine surfactant. These findings question whether the poor efficacy of GLSE could be explained by a lower bio-equivalence of its dose compared with beractant. However, it is not clear if GLSE would have performed better at a higher initial dose. Such a preparation would have to be sufficiently concentrated that the intra-tracheally administered volume does not exceed $4-5 \mathrm{~mL} / \mathrm{kg}$. Higher dose of poractant $(200 \mathrm{mg} / \mathrm{kg})$ can be administered in a small volume of $2.5 \mathrm{~mL} / \mathrm{kg}$, compared with 3 or $4 \mathrm{~mL} / \mathrm{kg}$ to administer $100 \mathrm{mg} / \mathrm{kg}$ of calfactant or beractant,

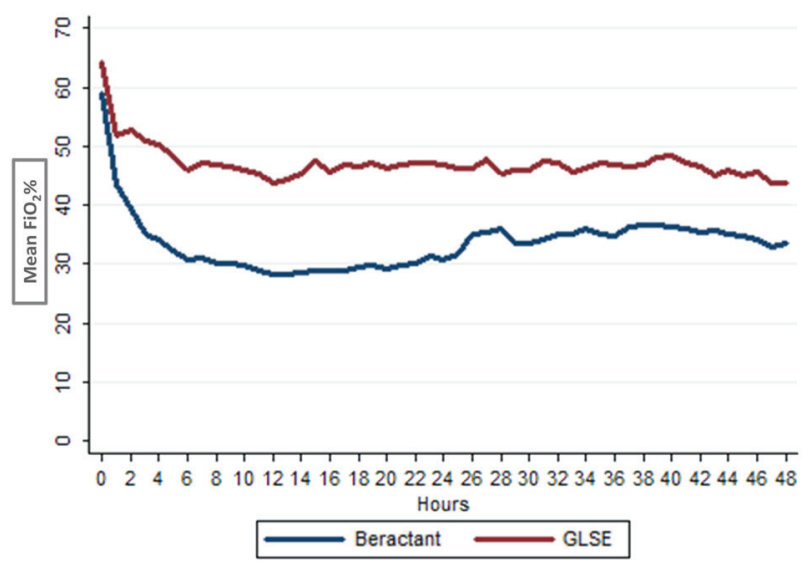

Fig. 2 Mean $\mathrm{FiO}_{2}$ values from 1 to $48 \mathrm{~h}$ postsurfactant in GLSE and Beractant groups respectively. Smaller volume of poractant facilitates quicker administration with fewer incidences of surfactant reflux and has definite cost savings from lower administration cost, less drug wastage, and reduced need for re-dosing [18]. At present, there are no dose equivalent trials comparing different animal-derived surfactants, and further research is needed.

Our study has several strengths. It is one of the rare examples of a new drug developed and tested in neonatal population with close collaboration between academia and industry in an LMIC setting. Despite the constraints of LMIC setting, we rigorously followed GCP. The trial was overseen by an independent DSMB, which provided a close oversight that culminated in the timely termination of the trial when concerns regarding lack of efficacy of GLSE emerged. The use of open-label beractant as a repeat dose, in both the groups, kept safety of the neonates above everything else, and was highly commended by the DSMB. The antenatal steroid use in the study population was high and all the study centers followed a uniform protocol for surfactant administration and re-dosing. The first dose was administered relatively early at a median age of $2.4 \mathrm{~h}$ in both the groups. We used an innovative system that ensured blinding of clinicians, in addition to investigators, parents, data teams, and statisticians. The study has some limitations. RDS was diagnosed clinically without the need for radiological confirmation. Hence, the possibility of the diagnosis being contaminated by other pulmonary conditions like pneumonia or asphyxia cannot be ruled out. The neonates were only followed until 36 weeks PMA due to logistic reasons, and long term outcomes were not studied.

In summary, in a multi-center, randomized controlled trial, we found that goat lung surfactant was inferior to beractant for the treatment of RDS in preterm neonates. Reasons to ascertain inferior efficacy of goat lung surfactant requires investigation and possible mitigating strategies in order to develop a low-cost and effective surfactant.

Table 5 Multivariable analysis of key outcomes

\begin{tabular}{|c|c|c|c|c|}
\hline Outcome & $\begin{array}{l}\text { GLSE } \\
n=52 \\
\mathrm{n}(\%)\end{array}$ & $\begin{array}{l}\text { Beractant } \\
n=46 \\
\mathrm{n}(\%)\end{array}$ & $\begin{array}{l}\text { Unadjusted odds ratio } \\
(95 \% \text { CI }), p \text { value }\end{array}$ & $\begin{array}{l}\text { Adjusted odds ratio }^{a} \\
(95 \% \mathrm{CI}), p \text {-value }\end{array}$ \\
\hline Death & $21(40.4 \%)$ & $14(30.4 \%)$ & $1.5(0.7-3.6) p=0.306$ & $1.13(0.40-3.29) p=0.815$ \\
\hline Repeat dose (one or more) & $34(65.4 \%)$ & $8(17.4 \%)$ & $9.0(3.5-23.3) p<0.001$ & $9.8(3.2-30.1) p<0.001$ \\
\hline $\begin{array}{l}\text { Need for mechanical ventilation at } 24 \mathrm{~h} \\
\text { after surfactant }\end{array}$ & $32 / 49(65.3 \%)$ & $15 / 46(32.6 \%)$ & $3.89(1.66-9.12) p=0.002$ & $5.1(1.5-17.2) p=0.009$ \\
\hline $\begin{array}{l}\text { Average } \mathrm{FiO}_{2} \text { required in first } 48 \mathrm{~h} \text { after } \\
\text { surfactant administration }(\%)\end{array}$ & $50.5 \pm 21.2$ & $33.3 \pm 14.5$ & $\begin{array}{l}\text { Difference in means } 17.2 \\
(9.8-24.6) p<0.001\end{array}$ & $\begin{array}{l}\text { Difference in means } 12.5 \\
(5.5-19.6) p<0.001\end{array}$ \\
\hline
\end{tabular}

$\mathrm{FiO}_{2}$-fractional inspired oxygen concentration

${ }^{a}$ Adjusted for study center and baseline characteristics that were substantially different (10\%) between group A and group B: sex of baby, rupture of membranes for more than $18 \mathrm{~h}$, antepartum hemorrhage, required positive pressure ventilation immediately after birth, receipt of delivery room CPAP, and InSurE (intubation, surfactant administration and extubation) 
Acknowledgements With the greatest humility, we acknowledge the contributions of the families and their precious newborns who participated in the trial and helped us reach to a meaningful conclusion of the study. We are indebted to a galaxy of experts who made selfless contributions to this trial without which this work would have never seen the light of the day: Prof MK Bhan (formerly DBT Secretary, Govt. of India), Prof Anand Pandit (KEM, Pune), Prof Vinod Bhutani (Stanford University, USA), Prof Haresh Kripalani (University of Pennsylvania, USA), Prof Betty Kirkwood (London School of Hygiene and Tropical Medicine, London), Prof Neerja Bhatla (AIIMS, New Delhi), Dr Nita Bhandari (Society for Applied Studies, New Delhi), Mr AB Ramteke (CDSA, Faridabad), Dr Shirshendu Mukherjee (Wellcome, UK), Dr David Millar (Royal Maternity Hospital, Belfast, UK), Dr Bethan Hughes (Wellcome, UK), Dr Diana Tay (Wellcome, UK), Dr Angela Miller (Wellcome, UK), Dr Nitya Wadhwa, (THSTI, Faridabad), Dr GB Nair (THSTI, Faridabad), Dr Rajiv Bahl (WHO, Geneva), Prof Allan Donner (Western University, Canada), Prof Ravinder Kaur (IIT, Delhi), Dr Shinjini Bhatnagar (THSTI, Faridabad), Dr Jose Carlos Martinez (formerly at WHO, Geneva), Prof Rakesh Lodha (AIIMS, New Delhi), Prof SN Dwivedi (AIIMS, New Delhi), Prof Harish Chellani (VMMC, New Delhi), Prof YK Gupta (AIIMS, New Delhi), Prof AP Dubey (MAMC, New Delhi), Dr Annam Visala (CDSCO, New Delhi), Prof Vijay Prakash Mathur (AIIMS, New Delhi) and CDSA team. We can never thank them enough!

We acknowledge Dr Manish Kumar DM, Research officers (Stephy Joe S, Swati Malik, Dolly Jillith), Research nurses (Anjana Devi, Arti Shukla, D Ponrani, Guna S, J. Gayathri, Josina C Jose, Jubilant James, Jyoti, Jyoti, Jyoti Gola, Jyoti Kadyan, Kushla Devi, Larishisha Risaw, Mahak, Manorama Bacheli, Meena G, Monika, Neeta, Neha Bisht, Neha Rohilla, Ponnarasi K, Pooja Chaudhary, Prachi Goswami, Princika Sagar, Rajni, R. Manju, R. Priya, Sara Sagar, Seethalakshmi. S, Shilpa Rani, Soshan Lunghar, Sushma Rani, Yogita, Keerthana. K, Kumari Soni), and secretarial staff (Sant Lal, Meenakshi, Dhiraj Batra) for their dedicated contribution to the trial.

We acknowledge Cadila Pharmaceuticals Ltd for providing free supply of Cadisurf. We acknowledge generous funding support and technical assistance from Wellcome, especially, Dr Shirshendu Mukherjee for being supportive and available for help all the time.

Funding Wellcome, UK funded the study (grant number 103386/Z/ $13 / \mathrm{Z}$ ) and publication of this supplement.

Author contributions KJ, SN, VB, PK, MJS, SR, MB, MJ, SV, SB, $\mathrm{DC}$, VKP, and RA prepared the study protocol and prepared the manuscript. KJ, SN, VB, PK, MJS, SR, MB, MJ, NP, VS, AJ, AT, KJ, AS, AB, SM, RN, SR, UV, AM, KA, JM, SA, AA, SM. SRB, TP, MK, ABR, SP, PKD, GV, SK, SG, AJ, CKN, AS, SK, MM, PN, GK, CPY, VK, RK, LA, and RA implemented the study. SV, KJ, and AB did data cleaning and statistical analysis. RA, YKG, NP, SS, AKD, and VKP modified the study protocol, supervised the implementation of the study and finalized the manuscript. RA acts as the guarantor of the paper.

\section{Compliance with ethical standards}

Conflict of interest The authors declare that they have no conflict of interest. Cadila Pharmaceutical Ltd, Ahmedabad, India provided goat lung surfactant free of cost. It had, however, no role in protocol development, implementation of the trial, or interpretation and publication of trial results.

Clinical trial registry name and registration number The trial was prospectively registered with Clinical Trials Registry-India (CTRI/
2015/07/005968; Registered on 06/07/2015) and clinicaltrials.gov (NCT02774044).

Ethics approval The study has been approved by Institutional ethics committee of all participating sites.

Regulatory approval The study had regulatory approval from Central Drugs Standard Control Organization (CDSCO) and Health Ministry's Screening Committee (HMSC), India.

Publisher's note: Springer Nature remains neutral with regard to jurisdictional claims in published maps and institutional affiliations.

Open Access This article is licensed under a Creative Commons Attribution 4.0 International License, which permits use, sharing, adaptation, distribution and reproduction in any medium or format, as long as you give appropriate credit to the original author(s) and the source, provide a link to the Creative Commons license, and indicate if changes were made. The images or other third party material in this article are included in the article's Creative Commons license, unless indicated otherwise in a credit line to the material. If material is not included in the article's Creative Commons license and your intended use is not permitted by statutory regulation or exceeds the permitted use, you will need to obtain permission directly from the copyright holder. To view a copy of this license, visit http://creativecommons. org/licenses/by/4.0/.

\section{References}

1. Seger N, Soll R. Animal derived surfactant extract for treatment of respiratory distress syndrome. Cochrane Database Syst Rev 2009;2:CD007836.

2. Pfister RH, Soll R, Wiswell TE. Protein-containing synthetic surfactant versus protein-free synthetic surfactant for the prevention and treatment of respiratory distress syndrome. Cochrane Database Syst Rev 2009;4:CD006180.

3. Sankar MJ, Gupta N, Jain K, Agarwal R, Paul VK. Efficacy and safety of surfactant replacement therapy for preterm neonates with respiratory distress syndrome in low- and middle-income countries: a systematic review. J Perinatol. 2016;36(Suppl 1): S36-48.

4. Salinas-Escudero G, Reyes-Lopez A, Garduno-Espinosa J, Villasis-Keever MA, Martinez-Valverde S, Munoz-Hernandez O. Economic evaluation of the use of exogenous pulmonary surfactants in preterm newborns in a Mexican population. Salud Publica Mex. 2012;54(Suppl 1):S73-81.

5. World Health Organization. WHO Model List of Essential Medicines. 18th list. April 2013. World Health Organization; 2018. http://www.who.int/medicines/publications/essentialmedicines4th EMLc_FINAL_web_8Ju113.pdf.

6. Arora NK, Swaminathan S, Mohapatra A, Gopalan HS, Katoch VM, Bhan MK, et al. Research priorities in Maternal, Newborn, \& Child Health \& Nutrition for India: An Indian Council of Medical Research-INCLEN Initiative. Indian J Med Res. 2017;145:611-22.

7. Narayanan S, Paul VK, Singh M, Pande JN, Rao DN, Vijayaraghvan M, et al. Preparation \& standardization of the goat lung surfactant extract. Indian J Med Res. 1998;107:113-7.

8. Walsh MC, Wilson-Costello D, Zadell A, Newman N, Fanaroff A. Safety, reliability, and validity of a physiologic definition of bronchopulmonary dysplasia. J Perinatol. 2003;23:451-6.

9. Yates HL, Newell SJ. Minidex: very low dose dexamethasone $(0.05 \mathrm{mg} / \mathrm{kg} /$ day $)$ in chronic lung disease. Arch Dis Child Fetal Neonatal Ed. 2011;96:F190-4. 
10. Rebello CM, Precioso AR, Mascaretti RS, Grupo Colaborativo do Estudo Brasileiro Multicentrico de S. A multicenter, randomized, double-blind trial of a new porcine surfactant in premature infants with respiratory distress syndrome. Einstein. 2014;12:397-404.

11. Charon A, Taeusch W, Fitzgibbon C, Smith GB, Treves ST, Phelps DS. Factors associated with surfactant treatment response in infants with severe respiratory distress syndrome. Pediatrics. 1989;83:348-54.

12. Segerer H, Stevens P, Schadow B, Maier R, Kattner E, Schwarz $\mathrm{H}$, et al. Surfactant substitution in ventilated very low birth weight infants: factors related to response types. Pediatri Res. 1991;30:591-6.

13. Hallman M, Merritt TA, Pohjavuori M, Gluck L. Effect of surfactant substitution on lung effluent phospholipids in respiratory distress syndrome: evaluation of surfactant phospholipid turnover, pool size, and the relationship to severity of respiratory failure. Pediatri Res. 1986;20:1228-35.
14. Halliday HL. Overview of clinical trials comparing natural and synthetic surfactants. Biol Neonate. 1995;67(Suppl 1):32-47.

15. Rudiger M, Tolle A, Meier W, Rustow B. Naturally derived commercial surfactants differ in composition of surfactant lipids and in surface viscosity. Am J Physiol Lung Cell Mol Physiol. 2005;288:L379-83.

16. Tolle A, Meier W, Rudiger M, Hofmann KP, Rustow B. Effect of cholesterol and surfactant protein B on the viscosity of phospholipid mixtures. Chem Phys Lipids. 2002;114:159-68.

17. Singh N, Halliday HL, Stevens TP, Suresh G, Soll R, Rojas-Reyes MX. Comparison of animal-derived surfactants for the prevention and treatment of respiratory distress syndrome in preterm infants. Cochrane Database Syst Rev 2015;12:CD010249.

18. Gerdes JS, Seiberlich W, Sivieri EM, Marsh W, Varner DL, Turck $\mathrm{CJ}$, et al. An open label comparison of calfactant and poractant alfa administration traits and impact on neonatal intensive care unit resources. J Pediatri Pharm Ther. 2006;11:92-100.

\section{Affiliations}

Kajal Jain ${ }^{1}$ - Sushma Nangia ${ }^{2}$ - Vishnu Bhat Ballambattu ${ }^{3}$. Venkataseshan Sundaram ${ }^{4} \cdot$ M. Jeeva Sankar ${ }^{1}$. Siddharth Ramji ${ }^{5}$. Sreenivas Vishnubhatla ${ }^{1}$ - Anu Thukral ${ }^{1}$ - Yogendra Kumar Gupta ${ }^{1,6}$ - Nishad Plakkal ${ }^{3}$. Mangalabharathi Sundaram ${ }^{7} \cdot$ Mamta Jajoo $^{8} \cdot$ Praveen Kumar $^{4} \cdot$ Kumutha Jayaraman $^{7} \cdot$ Ashish Jain $^{5} \cdot$ Arvind Saili $^{2}$. Anitha Murugesan ${ }^{7} \cdot$ Deepak Chawla $^{9} \cdot$ Srinivas Murki $^{10} \cdot$ Ruchi Nanavati $^{11} \cdot$ Suman Rao $^{12} \cdot$ Umesh Vaidya $^{13}$. Ashish Mehta ${ }^{14}$. Kamal Arora ${ }^{15}$ - Jayashree Mondkar ${ }^{16}$. Sugandha Arya ${ }^{17}$. Monika Bahl ${ }^{18}$. Alpana Utture ${ }^{11}$. Swati Manerkar ${ }^{16}$. Swarna Rekha Bhat ${ }^{12}$. Tushar Parikh $^{13}$. Manish Kumar ${ }^{14}$. Anurag Bajpai ${ }^{1}$. Sindhu Sivanandan ${ }^{3}$. Pawandeep Kaur Dhawan ${ }^{18}$. Gayatri Vishwakarma ${ }^{18}$. Sudhakar Bangera ${ }^{18}$. Sumit Kumar ${ }^{18}$. Shridhar Gopalakrishnan ${ }^{19}$ - Atul Jindal ${ }^{20}$. Chandra Kumar Natarajan ${ }^{21}$ - Anumeet Saini ${ }^{2} \cdot$ Sukanya Karunanidhi $^{3}$. Meenakshi Malik ${ }^{4}$ Parul Narang ${ }^{1}$ - Gurkirat Kaur ${ }^{5}$. Chander Prakash Yadav ${ }^{22}$ • Ashok Deorari ${ }^{1}$ - Vinod K. Paul ${ }^{1,23}$. Ramesh Agarwal ${ }^{1}$

1 All India Institute of Medical Sciences (AIIMS), New Delhi, India

2 Lady Hardinge Medical College (LHMC), New Delhi, India

3 Jawaharlal Institute of Postgraduate Medical Education and Research (JIPMER), Puducherry, India

4 Postgraduate Institute of Medical Education and Research (PGIMER), Chandigarh, India

5 Maulana Azad Medical College (MAMC), New Delhi, India

6 Translational Health Sciences and Technology Institute, Faridabad, India

7 Institute for Child Health (ICH), Chennai, India

8 Chacha Nehru Bal Chikitsalaya (CNBC), New Delhi, India

9 Government Medical College \& Hospital, Chandigarh, India

10 Fernandez Hospital, Hyderabad, India

11 King Edward Memorial Hospital, Mumbai, India

12 St. John's Medical College, Bangalore, India
13 King Edward Memorial Hospital, Pune, India

14 Arpan Newborn Care center and Sterling NICU, Ahmedabad, India

15 Dayanand Medical College and Hospital, Punjab, India

16 Lokmanya Tilak Municipal General Hospital (SION Hospital), Mumbai, India

17 Safdarjung Hospital, New Delhi, India

18 Clinical Development Services Agency, Faridabad, India

19 Command Hospital, Panchkula, India

20 All India Institute of Medical Sciences (AIIMS), Raipur, India

21 Cloudnine Hospital, Chennai, India

22 National Institute of Malaria Research, New Delhi, India

23 National Institution for Transforming India (NITI Aayog), Government of India, New Delhi, India 